\title{
WILDERNESS MEDICAL SOCIETY CLINICAL PRACTICE GUIDELINES
}

\section{Wilderness Medical Society Clinical Practice Guidelines for the Prevention and Treatment of Heat Illness: 2019 Update}

\author{
Grant S. Lipman, MD ${ }^{1}$; Flavio G. Gaudio, $\mathrm{MD}^{2}$; Kurt P. Eifling, $\mathrm{MD}^{3}$; Mark A. Ellis, MD ${ }^{4}$; \\ Edward M. Otten, $\mathrm{MD}^{5}$; Colin K. Grissom, MD ${ }^{6}$ \\ ${ }^{1}$ Department of Emergency Medicine, Stanford University School of Medicine, Stanford, CA; ${ }^{2}$ Department of Emergency Medicine, New York-Presbyter- \\ ian Hospital/Weill Cornell Medical College, New York, NY; ${ }^{3}$ Division of Emergency Medicine, Larner College of Medicine at the University of Vermont, \\ Burlington, VT; ${ }^{4}$ Department of Emergency Medicine, Spartanburg Regional Healthcare System, Spartanburg, SC; ${ }^{5}$ Department of Emergency Medicine, \\ University of Cincinnati, Cincinnati, $\mathrm{OH} ;{ }^{6}$ Pulmonary and Critical Care Division, Intermountain Medical Center and the University of Utah, Salt Lake \\ City, UT
}

\begin{abstract}
The Wilderness Medical Society convened an expert panel in 2011 to develop a set of evidence-based guidelines for the recognition, prevention, and treatment of heat illness. We present a review of the classifications, pathophysiology, and evidence-based guidelines for planning and preventive measures, as well as best practice recommendations for both field- and hospital-based therapeutic management of heat illness. These recommendations are graded based on the quality of supporting evidence and balance the benefits and risks or burdens for each modality. This is an updated version of the original Wilderness Medical Society Practice Guidelines for the Treatment and Prevention of Heat-Related Illness published in 2013.
\end{abstract}

Keywords: heat stroke, hyperthermia, prevention, recognition, treatment

\section{Introduction}

Heat illness is a common occurrence worldwide. The European heat wave of 2003 resulted in at least 70,000 fatalities, ${ }^{1}$ and in the last decade the United States averaged over 600 deaths annually associated with excessive heat exposure. ${ }^{2}$ Currently, heat illness is the leading cause of morbidity and mortality among US high school athletes. ${ }^{3}$ Heat stroke mortality approaches $10 \%{ }^{4}$ and when presenting with hypotension increases to $33 \% .{ }^{5}$ Outcome is directly attributed to both the magnitude and duration of hyperthermia, ${ }^{6-8}$ making early recognition and treatment a priority. The Wilderness Medical Society convened an expert panel to develop a set of practice guidelines for the recognition, prevention, and treatment of heat illness. We present a review of the classifications, pathophysiology, and evidence-based guidelines for planning and preventive measures, as well as best practice recommendations for both field- and hospital-based therapeutic management of heat illness. Although the spectrum

Corresponding author: Grant S. Lipman, MD, Department of Emergency Medicine, Stanford University School of Medicine, Suite \#350, 900 Welch Rd, Palo Alto, CA 94304; e-mail:

grantlip@hotmail.com.

Submitted for publication June 2018.

Accepted for publication October 2018. of heat illness is discussed, this practice group's focus was on the exploration of exertional heat stroke (EHS), which is synonymous with the term "heat stroke" in this article unless otherwise specified.

\section{Methods}

Specialists in emergency medicine, primary care, and critical care from both civilian and military backgrounds were chosen based on their clinical or research experience. In $2011,{ }^{9}$ and for subsequent practice guideline updates, ${ }^{10}$ relevant articles were identified through the PubMed database using the following key words: hyperthermia, heat stroke, heat illness, heat syncope, and heat exhaustion. This was supplemented by a hand search of articles from references in the initial PubMed search. Studies in these categories, including randomized controlled trials, observational studies, and case series, were reviewed. Abstractonly reports were not included. Conclusions from review articles were cited to provide background information but were not considered in the formulation of recommendation grades. The panel used a consensus approach to develop recommendations for the recognition and management of heat illness, with level of evidence assigned according to methodology stipulated by the American College of Chest 
Physicians for grading of evidence and recommendations (online Supplementary Table 1). These recommendations are graded based on the quality of supporting evidence and balance between the benefits and risks or burdens for each modality or intervention.

\section{Definition of heat illness}

Heat illness can be manifested as a spectrum of disease from minor to severe, such as heat cramps, heat syncope, heat exhaustion, and life-threatening heat stroke. Hyperthermia is a deviation above the body's normal physiologic setpoint and should be considered separately from the concept of heat illness. It is an expected physiologic response when core body temperature rises as a result of exposure to elevated ambient temperatures or when internally generated heat from muscular activity accumulates faster than it can be dissipated. Hyperthermia is a natural outcome of exertion, and increased metabolic rate has been shown to be the most important factor in elevation of body temperature. ${ }^{11}$ Studies of asymptomatic runners have found 15 to $56 \%$ with core temperatures $\geq 40^{\circ} \mathrm{C}$ and $11 \% \geq 42^{\circ} \mathrm{C}^{12,13}$ As such, absolute temperature thresholds alone should not be routinely applied to asymptomatic individuals as a pathologic indicator of heat illness.

As with any syndrome, the terms used to define heat illness do not necessarily confer direct cause and effect but rather a strong contextual association that may have descriptive, prognostic, and epidemiological merit, if not pathophysiologic precision. ${ }^{14,15}$ Heat cramps were initially defined in the 1930s to describe the clinical phenomenon of involuntary diffuse large-muscle contractions associated with exertion in hot environments. ${ }^{16}$ These heat cramps are likely distinct from the focal muscle cramping in an athlete during repetitive exercises. ${ }^{17}$ Dehydration and electrolyte disturbances have been associated with heat cramps,${ }^{18}$ and isotonic rehydration has been found to be restorative. ${ }^{16}$ Heat edema is a benign self-limiting condition. Interstitial fluid accumulates in dependent extremities as a result of hydrostatic pressure, vascular leak, and cutaneous vasodilation. Heat syncope refers to a multifactorial syndrome involving transient loss of consciousness in the context of heat exposure with a relatively rapid return to normal function and baseline. Contributing factors may include peripheral vasodilation, orthostatic pooling of blood, prolonged standing, advanced age, dehydration, and coexisting medical conditions such as ischemic heart disease that reduces cardiac output. Although syncope can occur in both milder and more severe forms of heat illness, heat syncope generally refers to a more benign clinical condition that should resolve with rest and possibly rehydration at comfortable ambient temperatures. ${ }^{19,21}$ Syncope may also occur during exertion from impaired baroreceptor reflex and lower extremity venous pooling in the absence of hyperthermia or dehydration, a syndrome known as exercise-associated collapse. ${ }^{19}$

Heat exhaustion results from exposure to high ambient temperature or strenuous exertion. It manifests as a constellation of symptoms that range from uncomfortable to debilitating ${ }^{6,21}$ and may limit continuation of exercise in the heat. ${ }^{6}$ Symptoms are variable and may include weakness, fatigue, thirst, headache, nausea, dizziness, and muscle aches. ${ }^{21}$ This mild to moderate heat illness may progress to heat stroke if left untreated or unrecognized in a hot environment, although heat stoke does occur as a fulminant illness without preceding heat exhaustion. Heat stroke is traditionally defined as a core temperature above $40^{\circ} \mathrm{C}\left(104^{\circ} \mathrm{F}\right)$ with central nervous system involvement (eg, encephalopathy, seizures, or coma). Heat stroke is generally divided into 2 categories: classic heat stroke resulting from passive exposure to high environmental temperatures and EHS resulting from pathologic (nonphysiologic) hyperthermia during strenuous exercise (Table1). ${ }^{22}$

\section{Heat dissipation and pathophysiology}

Heat loss is controlled by peripheral centers in the skin and organs and the central nervous system via the

Table 1. Categories of heat illness

\begin{tabular}{|c|c|}
\hline Condition & Definition \\
\hline Hyperthermia & $\begin{array}{l}\text { A rise in body temperature above the } \\
\text { hypothalamic set point when heat-dissipating } \\
\text { mechanisms are impaired (by clothing or } \\
\text { insulation, drugs, or disease) or overwhelmed } \\
\text { by external (environmental) or internal } \\
\text { (metabolic) heat production. }\end{array}$ \\
\hline Heat edema & $\begin{array}{l}\text { Dependent extremity swelling due to } \\
\text { interstitial fluid pooling. }\end{array}$ \\
\hline Heat cramps & $\begin{array}{l}\text { Exercise-associated painful involuntary muscle } \\
\text { contractions during or immediately after } \\
\text { exercise. }\end{array}$ \\
\hline Heat syncope & $\begin{array}{l}\text { Transient loss of consciousness with } \\
\text { spontaneous return to normal mentation. }\end{array}$ \\
\hline $\begin{array}{l}\text { Heat } \\
\text { exhaustion }\end{array}$ & $\begin{array}{l}\text { Mild to moderate heat illness due to exposure } \\
\text { to high environmental heat or strenuous } \\
\text { physical exercise; signs and symptoms } \\
\text { include intense thirst, weakness, discomfort, } \\
\text { anxiety, dizziness, syncope; core temperature } \\
\text { may be normal or slightly elevated }>37^{\circ} \mathrm{C} \\
\left(98.6^{\circ} \mathrm{F}\right) \text { but }<40^{\circ} \mathrm{C}\left(104^{\circ} \mathrm{F}\right) \text {. }\end{array}$ \\
\hline Heat stroke & $\begin{array}{l}\text { Severe heat illness characterized by a core } \\
\text { temperature }>40^{\circ} \mathrm{C}\left(104^{\circ} \mathrm{F}\right) \text { and central } \\
\text { nervous system abnormalities such as altered } \\
\text { mental status (encephalopathy), seizure, or } \\
\text { coma resulting from passive exposure to } \\
\text { environmental heat (classic heat stroke) or } \\
\text { strenuous exercise (exertional heat stroke). }\end{array}$ \\
\hline
\end{tabular}


hypothalamus, with a greater cooling response to temperature elevation via central sensors. ${ }^{23} \mathrm{~A}$ temperature gradient exists between the body core and skin that promotes heat dissipation when core temperature is higher than surface temperature. A rise in blood temperature by less than $1^{\circ} \mathrm{C}$ triggers hypothalamic thermoregulation to increase blood flow to the skin by up to $8 \mathrm{~L} \cdot \mathrm{min}^{-1}$ via sympathetic cutaneous vasodilation, with sixfold blood flow increases to the forearms and the arteriovenous anastomotic microvascular structures deep to the glabrous skin areas, with their unique intrinsic heat transfer capabilities. ${ }^{24,25}$ As blood is shunted to the periphery to facilitate heat loss, renal and splanchnic perfusion is reduced by $30 \%{ }^{24}$

However, when the core temperature increases during exercise and skin temperature also rises as a result of the environment or internal heat production, heat dissipation is reduced. Similarly, when the body's metabolic heat production outpaces heat transfer, core temperature rises, and heat illness can occur. ${ }^{26}$ Heat stroke occurs when internal core temperatures rise above a critical level, leading to a cascade of cellular and systemic responses. These responses include thermoregulatory dysfunction, an acute phase response, and a heat shock protein response. The acute phase response to heat stress involves an inflammatory reaction of interleukins, cytokines, and proteins that progresses in a sequence similar to that seen in sepsis. It is theorized that an exaggerated acute phase and inflammatory response mark the progression from heat stress to heat stroke, possibly incited by the hypoperfused gastrointestinal tract. ${ }^{22}$ Increased mucosal permeability from inflammatory mediators allows endotoxins from the gut to enter the systemic circulation. This combination of endotoxemia and cascade of inflammatory cytokines leads to alterations in the microcirculation, further endothelial and tissue injury, and impaired thermoregulation, thus precipitating heat stroke and hypotension. An overlapping hypothesis presupposes that at a similar threshold temperature, the expression of protective heat-shock proteins is altered, decreasing their ability to prevent thermal denaturation of structural proteins and enzymes that start to fail at a cellular level, with ensuing end organ dysfunction. ${ }^{22,27}$ At critical levels of hyperthermia, heat causes direct tissue injury and death via apoptosis or necrosis, with the severity of injury dictated by both the level and duration of thermal stress. ${ }^{28,29}$ This complex constellation of overlapping events leads to thermoregulatory failure, heat stroke, and circulatory shock.

\section{Prevention and planning}

The proverb that "an ounce of prevention is worth a pound of cure" is especially apt in light of the potentially fatal nature of heat illness. Deliberate strategies for prevention should be included when planning for activities with a credible risk. Structured risk assessments can be built and validated for population-level use, ${ }^{30,31}$ or the practitioner considering a particular scenario should consider the risk incurred by the individual participant's factors including physiology, the environment, and the planned athletic activity. ${ }^{32}$

\section{INDIVIDUAL FACTORS}

Any condition that limits heat loss through the skin may lead to heat retention, including hypohydrosis, extensive scars, and diminished cardiopulmonary reserve at the extremes of age. Small studies have linked acute sunburn with impaired sweating, which persisted for $7 \mathrm{~d}$, considerably longer than the associated pain and erythema. ${ }^{33,34}$ Impaired sweating is a risk factor for heat accumulation, but otherwise the risks of sunburn are of indeterminate clinical significance.

Certain drugs can predispose individuals to heat injury by 2 primary pathways, increased heat production resulting from drug actions and compromised function of thermoregulatory centers (Table 2) ${ }^{35,36}$ Moderate caffeine intake appears to have no detrimental effect. ${ }^{18} \mathrm{~A}$ large prospective study of military recruits found a significantly increased risk of heat illness among those who were obese or overweight compared with fitter individuals. ${ }^{37}$

Heat acclimatization, as induced by 1 to $2 \mathrm{~h}$ of heatexposed exertion per day over 10 to $14 \mathrm{~d}$, results in reproducible adaptations that increase the body's ability to tolerate and divest heat. ${ }^{38-40}$ These adaptations may persist for up to a month. ${ }^{41,42}$ Evidence suggests that a bout of heat stroke may acutely reset these thermoregulatory adaptations and cause elevated risk for subsequent heat injury for months after the initial event, ${ }^{43}$ although case reports indicate that heat tolerance can be recovered fully. ${ }^{44,45}$ Individuals with high levels of cardiopulmonary fitness tolerate more activity

Table 2. Medications and drugs that may contribute to heat illness

Alcohol

Alpha adrenergics

Amphetamines

Anticholinergics

Antihistamines

Antipsychotics

Benzodiazepines

Beta blockers

Calcium channel blockers

Clopidogrel

Cocaine

Diuretics

Laxatives

Neuroleptics

Phenothiazines

Thyroid agonists

Tricyclic antidepressants 
in heat-strained conditions and acclimatize to heat more rapidly because they have increased sweat volumes and higher subjective tolerance for activity when hyperthermic.

The most readily modifiable physiologic risk factor is hydration status. Although endurance athletes may comfortably tolerate weight losses of 3 to $4 \%$ during events, ${ }^{46,47}$ fluid losses that result in a 2 to $3 \%$ decrease in body weight correlate with greater core temperatures at a given work load in the heat. ${ }^{39,48,49}$ Dehydration has been found to increase physiologic strain, decrease sweat rates, increase perceived exertion, and increased core temperatures. ${ }^{23,50,51}$

Hyperhydration before activity has not been shown to have a significant effect on heat tolerance, nor has active body cooling before activity. ${ }^{52}$ One investigation on the effect of sex as a risk factor on thermal recovery was confounded by body mass index differences, such that no conclusion could be reached. ${ }^{53}$ The luteal phase of the menstrual cycle, which is associated with increased core temperatures, does not appear to induce heat intolerance in women on oral contraceptive pills. ${ }^{54}$ The physiology of pediatric and elderly populations differs enough from healthy adults to warrant special considerations that are outside this panel's scope but are discussed at length elsewhere. ${ }^{55-57}$

Recommendations. Screen for significant pre-existing medical conditions (1B). Minimize use of medications that could limit the thermoregulatory response (1C). Recognize that an overweight body habitus is associated with greater risk of heat illness (1B). Promote regular aerobic activity before heat exposure (1C). Allow for acclimatization with 1 to $2 \mathrm{~h} \cdot \mathrm{d}^{-1}$ of heat-exposed exertion for at least $8 \mathrm{~d}$ (1C). Ensure euhydration before activity (1B). Ensure ongoing rehydration with a "drink to thirst" approach sufficient to prevent $>2 \%$ loss of body weight (1B). Consider history of heat injury as a reversible risk factor for recurrence (1C).

\section{ENVIRONMENTAL CONSIDERATIONS}

The body and the environment exchange heat through several mechanisms: conduction (heat transfer from the body to the surrounding environment along a temperature gradient by direct contact), evaporation (heat transfer from the body to sweat, resulting in transition of water from the liquid to vapor phase), thermal radiation (infrared rays given off by any mass as a function of the temperature of that mass), or convection (transfer of heat from the body to free fluids or gas moving across the skin surface).

As the environmental temperature increases, the body will eventually incur a net heat gain through conductive, convective, and radiative processes, leaving evaporation as the only cooling mechanism. The vaporization of $1.7 \mathrm{~mL}$ of sweat consumes $1 \mathrm{kcal}$ of heat ${ }^{58}$; however, evaporative cooling is less effective in highly humid environments, which have a lower water vapor pressure difference between the sweat on the skin and the water in the surrounding air. The wet-bulb globe temperature index (WBGT) is a composite index of temperature, humidity, and solar radiation that expresses the total thermal strain that an individual experiences. A series of WBGT values can be designated as cautionary warnings and triggers to activate guidelines for rehydration, active cooling, and limitations (or even cancellation) of physical activity. ${ }^{34}$ An alternative to the WBGT that is more readily available is the heat index, which is a measure of the contribution that high temperature and high humidity (expressed as either relative humidity or dew point temperature) make in reducing the body's ability to cool itself. Although the wet bulb globe temperature is a metric likely not readily available to individual medical practitioners, its current use by military, ${ }^{59}$ occupational, ${ }^{60}$ and civilian groups ${ }^{26,55}$ makes it the standard when discussing environmental thermal strain and choosing activity levels for ambient conditions. Guidelines that correlate the heat index with the risk of heat injury and outline parameters for limiting physical activity are readily available. ${ }^{61}$

Recommendation. WBGT should be used for the assessment of heat risk (1A).

\section{ACTIVITY CONSIDERATIONS}

The metabolic thermal output of an activity is the product of its intensity and duration. The accumulation of heat by the body is tempered in some circumstances by an activity that can enhance heat transfer with the environment (eg, water convection on a swimmer or wind past a cyclist). Occupational, ${ }^{60,62}$ military, ${ }^{59}$ and medical ${ }^{24}$ guidelines recommend breaks in proportion to metabolic demand and ambient conditions, but there are few studies examining how to optimize the dosing of breaks.

Recommendation. Consider which mechanisms of heat accumulation or dissipation are dominant during an activity, and consider heat loss as a key feature of breaks (1C).

\section{CLOTHING AND EQUIPMENT}

Clothing or other equipment worn during an activity may limit or enhance the body's thermoregulatory efficiency. Of particular importance is equipment that occludes regions of skin, resulting in compromise of evaporative, convective, radiative, or conductive heat transfer. For example, the American football uniform prevents full heat exchange across much of the torso and head and can therefore contribute to heat accumulation, ${ }^{63}$ similar to military helmets and body armor ${ }^{64}$ Preventing heat exchange may be protective, as in the case of firefighting gear that prevents heat in a superheated environment from entering the body by conduction or radiation. Sports medicine guidelines and 
military occupational guidelines have set examples of systematic reductions in clothing and equipment based on WBGT thresholds. ${ }^{26,65}$

Recommendation. Clothing and equipment for a given activity should be evaluated and modified as needed to optimize evaporative, convective, conductive, and radiative heat exchange or isolation (1C).

\section{Field treatment}

Optimal field management of heat illness may be challenging because of resource limitations or extreme settings. The ideal treatment, as emphasized in the previous section, is prevention via avoiding high-exertion activities in exposed or hot areas. The method and aggressiveness of cooling in the field depend on the type of heat illness encountered (Table 3). Regardless of the underlying cause, removal from the heat and rapid cooling is critical because the extent of morbidity is directly related to both to the degree and duration of hyperthermia. ${ }^{8,37,66-69}$ All treatment in the field is first directed to stabilization of the patient's airway, breathing, and circulation before proceeding to more specific cooling therapy. If no life-threatening complications exist, the implementation of on-site cooling before evacuation should be implemented (Figure 1). ${ }^{26}$ In transitioning patient care to emergency medical service providers, it is important to communicate any cooling techniques begun in the field and to emphasize continued cooling of the patient by best available means en route to the destination.

\section{MINOR HEAT ILLNESS TREATMENT}

There is scant evidence supporting treatments of minor and moderate heat illness. Most treatments are anecdotal but effective and generalizable from the evidence-based treatment for more severe forms of heat illness (Table 3). Heat cramps, which are historically described as generalized, ${ }^{16}$ differ from the focal exercise-associated muscle cramps seen in endurance athletes. Heat cramps are relieved with oral salt solutions or electrolyte replacement that may be isotonic or hypertonic, ${ }^{16}$ compared with exercise-associated muscle cramps that occur with neuromuscular fatigue and are relieved with passive stretching. ${ }^{70}$ Heat edema is reversed by extremity elevation or wearing of compression stockings. Diuretics are ineffective and may worsen volume depletion. ${ }^{71}$

Heat syncope by definition is self-limiting. After consideration of other medical causes of syncope or resultant trauma from a fall, treatment consists of ensuring replacement of vascular volume with isotonic oral fluids and rest in a cool environment. ${ }^{19}$ Individuals at risk for heat syncope should move often and flex their larger leg muscles to prevent peripheral pooling of blood from cutaneous
Table 3. Heat illness treatments

\begin{tabular}{|c|c|c|}
\hline $\begin{array}{l}\text { Severity of } \\
\text { heat-related } \\
\text { illness }\end{array}$ & Diagnosis & Treatment \\
\hline Mild & $\begin{array}{l}\text { Heat } \\
\text { cramps } \\
\text { Heat } \\
\text { edema }\end{array}$ & $\begin{array}{l}\text { Oral isotonic or hypertonic } \\
\quad \text { fluid replacement } \\
\text { Extremity elevation } \\
\text { Compression stockings }\end{array}$ \\
\hline Moderate & $\begin{array}{l}\text { Heat } \\
\text { syncope }\end{array}$ & $\begin{array}{l}\text { Remove from heat source } \\
\text { Passive cooling } \\
\text { Oral isotonic or hypertonic } \\
\text { fluid hydration }\end{array}$ \\
\hline & $\begin{array}{l}\text { Heat } \\
\text { exhaustion }\end{array}$ & $\begin{array}{l}\text { Remove from heat source } \\
\text { Evaporative, convective, or } \\
\text { conductive cooling } \\
\text { Oral or intravenous isotonic } \\
\text { or hypertonic fluid hydration }\end{array}$ \\
\hline Severe & $\begin{array}{l}\text { Heat } \\
\text { stroke }\end{array}$ & $\begin{array}{l}\text { Remove from heat source } \\
\text { Supportive care of airway, } \\
\quad \text { breathing, and circulation } \\
\text { Cold water immersion } \\
\text { Whole-body conductive cooling } \\
\text { Intravenous hydration }^{\text {a }} \\
\text { Evacuation }^{\text {b }}\end{array}$ \\
\hline
\end{tabular}

\footnotetext{
${ }^{\mathrm{a}}$ Intravenous hydration with isotonic ( $0.9 \%$ sodium chloride) or hypertonic (D5NS) fluids, with 3\% sodium chloride indicated if concern for exercise-associated hyponatremia as cause of encephalopathy.

b Initiate emergency medical services if unable to rapidly cool patient, prolonged encephalopathy, or concern of multiorgan dysfunction.
}

vasodilation. An individual with heat syncope is likely underacclimatized to the heat, and caution is warranted before immediate return to regular activity.

Heat exhaustion, like heat stroke, results from a combination of both cardiovascular and thermal strain, and various forms of rest and whole-body cooling are dictated by severity of symptoms. Mild cases generally resolve with removing the patient from the hot environment, cessation of physical activity, and rehydration with oral isotonic fluids. Severe heat exhaustion typically has more pronounced volume depletion and may require intravenous replacement of fluids as well as conductive and convective cooling. Because heat exhaustion can lead to cessation of physical activity and collapse, ${ }^{6}$ it is important to actively reverse the process of heat exhaustion, which can progress to heat stroke without proper cooling techniques. Case reports have linked heat exhaustion or acute heat stress to precipitating electrocardiogram changes, symptomatic arrhythmias, and cardiac arrest with features of underlying Brugada syndrome. ${ }^{72,73}$

Recommendation. Heat syncope patients whose event is recurrent and inconsistent with exercise-associated collapse or other clear explanation should be referred for further cardiology diagnostics (2C). 


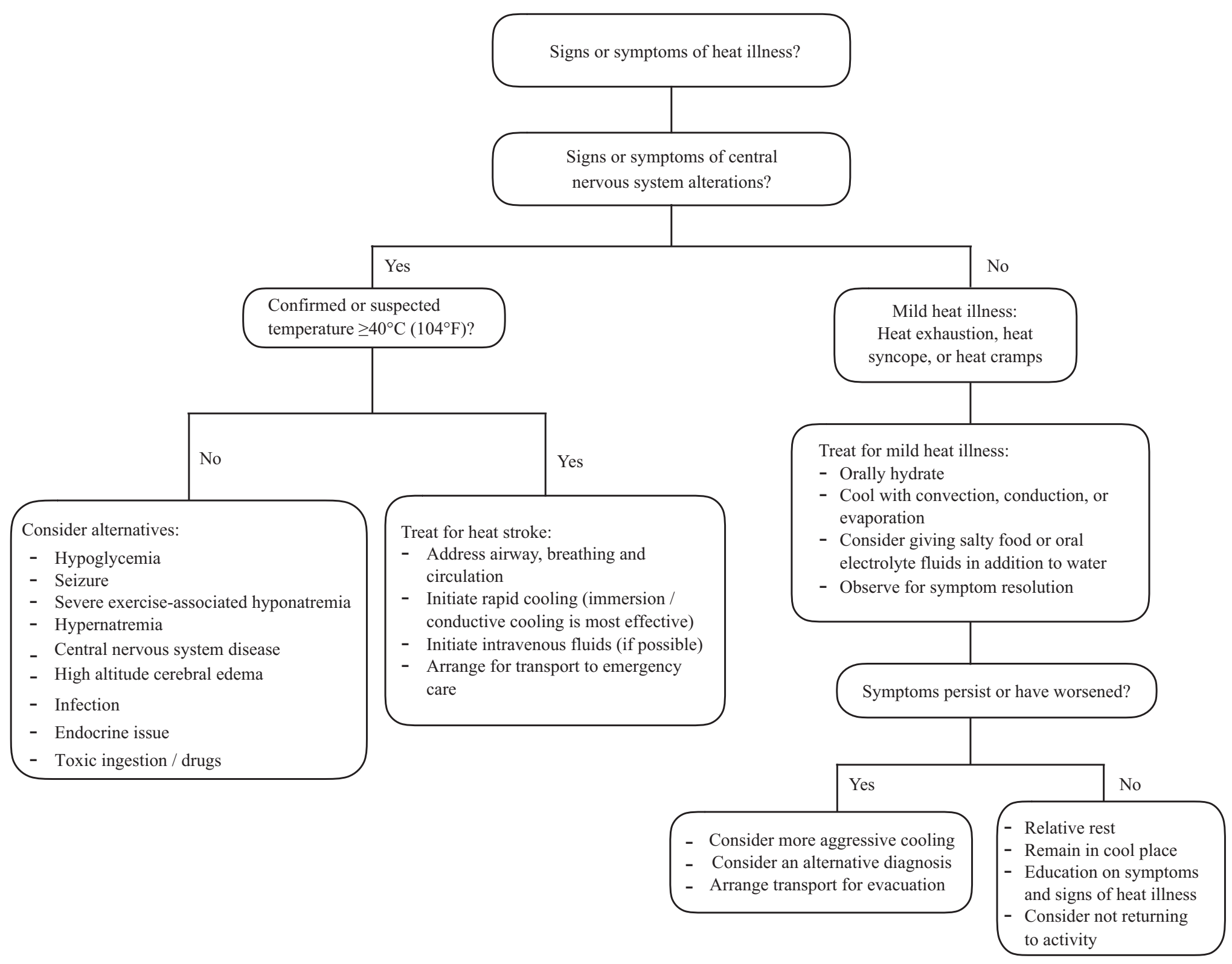

Figure 1. Heat illness treatment algorithm. 


\section{TEMPERATURE MEASUREMENT}

When possible, obtaining an accurate body temperature is an important diagnostic step in differentiating heat stroke from less severe heat illness. Rectal temperature is widely considered the standard field measurement, ${ }^{25,67}$ because it is a reliable and practical measure of core temperature that is more accurate than temporal, axillary, oral, or aural thermometry. ${ }^{74,75}$ Esophageal and ingestible thermistors have been validated and provide a more accurate measurement of core temperature but are impractical in the wilderness setting. Rectal temperature measurement carries implicit challenges in maintaining patient privacy and hygiene, so initial assessment and aggressive cooling should be implemented based on the clinical suspicion, regardless of the degree of hyperthermia or mode of measurement.

Recommendations. When available, rectal temperature should be considered the most accurate measurement of core hyperthermia compared to axillary, oral, or aural thermometry (1B). In a hyperthermic individual with an altered sensorium, the initiation of empiric cooling for heat stroke should not be delayed by a measurement value that may be below the diagnostic threshold of $40^{\circ} \mathrm{C}(1 \mathrm{~B})$.

\section{PASSIVE COOLING}

Simple measures can be easily taken to reduce the patient's exposure to heat. Moving the victim into the shade can externally decrease the ambient temperature; however, this is most effective when temperatures are $<20^{\circ} \mathrm{C}\left(68^{\circ} \mathrm{F}\right){ }^{67}$ Conduction of heat from the ground can be decreased by placing the victim on cool ground, if available, or on an insulating barrier such as sleeping pad or sleeping bag. Loosening or removing any tight-fitting clothing to optimize air circulation aids in convective heat exchange. ${ }^{76}$

Recommendation. Passive cooling measures should be used to minimize thermal strain and maximize heat loss (1C).

\section{HYDRATION}

Euhydration is an important factor in reducing hyperthermia. ${ }^{76,77}$ Body water losses through increased sweat rates, vomiting, diarrhea, or insufficient oral intake increase the risk of potential heat injury resulting from poor hydration status. Dehydration predisposes patients to hyperthermia by decreasing sweat rates and increases thermal strain at a given temperature. ${ }^{50,77-79}$ Oral and intravenous hydration have been shown to be equally effective in replenishing water deficiencies related to heat stress. ${ }^{77,80}$

Recommendation. Dehydration should be minimized in heat illness (1C).
Optimizing hydration in heat stroke decreases both the cardiovascular and thermal strain. In a heat stroke victim with altered mental status and risk of seizure, the intravenous route minimizes aspiration risk and subsequent airway compromise. Few data exist on the optimal intravenous fluid type and amount relating specifically to heat illness. Because those with EHS may be volume depleted from insensible fluid losses, the reasonable choices of replenishment are 1 to $2 \mathrm{~L}$ of isotonic ( $0.9 \%$ normal saline or normal saline with 5\% dextrose) fluids. Because heat stroke can occur in both euhydrated and dehydrated individuals, care should be taken to not overhydrate patients (especially those with coronary comorbidity) because this may increase the risk of pulmonary edema. ${ }^{79}$ Any effort to provide hydration in suspected heat stroke should not delay rapid whole-body cooling. ${ }^{82}$ If intravenous hydration is provided, field monitoring of blood pressure, heart rate, lightening of urine color, and increase in urine output can help guide patient response and fluid status.

Recommendation. Intravenous fluids should be used for rehydration in EHS (1B).

Symptomatic exercise-associated hyponatremia may present similarly to heat exhaustion, ${ }^{21}$ and the presence of altered mental status (eg, obtundation, coma, or seizures) without other explanation, such as hypoglycemia or trauma, in the absence of hyperthermia may indicate severe exercise-associated hyponatremia. This is a critical illness that ideally should be confirmed with serum sodium measurement, but in the absence of point-of-care testing the patient should empirically be resuscitated with up to $3,100 \mathrm{~mL} \mathrm{3 \%}$ sodium chloride boluses given every $10 \mathrm{~min}$, or until resolution of altered mental status, with rapid transfer to a medical facility. ${ }^{83}$

\section{COLD WATER IMMERSION THERAPY}

Cold water immersion therapy is the optimal field treatment to achieve rapid temperature reduction below critical levels in heat stroke. Immersion is a conductive method of cooling that takes advantage of water's high thermal conductivity, which is 24 times greater than that of air, ${ }^{84}$ and the high thermal gradient that exists between cold water and skin, ${ }^{85}$ which translates into a greater capacity for heat transfer. The colder the water, the faster the rate of cooling. ${ }^{86}$ The theoretical concern that cold-water immersion causes peripheral vasoconstriction and shivering that slow cooling, or may even increase the core temperature, is a prevalent misconception, possibly stemming from a misinterpretation of the "Currie response." ${ }^{87}$ This 18 th century observation found an increase in the core temperature of shivering normothermic individuals by 0.1 to $0.2^{\circ} \mathrm{C}$. Although shivering 
has been observed in immersions lasting longer than $10 \mathrm{~min}$ in healthy volunteers, ${ }^{88,89}$ such shivering may be less problematic in actual heat stroke patients with failing thermoregulation. ${ }^{90}$ In addition, the hindrance of cooling EHS by heat-generating shivering has been physiologically refuted. ${ }^{86,91}$ Cold-water immersion is achieved by removing insulating clothes and equipment and submersing the patient's trunk and extremities in a bath of cold water or tub of ice water. Alternatively, water may be applied onto a patient covered in crushed ice and lying on a plastic sheet or tarp with its sides folded upright to keep the slurry in place ("tarp taco"). ${ }^{92}$ Ice water cooling has been shown to be twice as rapid in reducing core temperature as covering the body in soaked towels to enhance evaporative cooling $\left(0.2^{\circ} \mathrm{C} \cdot \min ^{-1}\right.$ vs $\left.0.1^{\circ} \mathrm{C} \cdot \min ^{-1}\right){ }^{66}$

In the field, using a natural body of water such as a stream, pond, river, or lake may be another treatment option. Special care should be taken to protect against currents and to ensure the head does not go underwater and the airway is protected; the patient should never be left alone owing to risk of aspiration and drowning. In lieu of a cold-water source, repeated dousing with cold water or snow, if available, is encouraged. Multiple military studies on immersion cooling of comparatively young and healthy EHS patients boast a $0 \%$ fatality rate, ${ }^{93}$ strongly supporting that rapid treatment with this cooling modality has the best outcomes.

Recommendation. Cold water immersion is the optimal cooling method for heat stroke (1A).

\section{EVAPORATIVE COOLING}

If immersion or conductive cooling is unavailable, evaporative cooling measures should be initiated by loosening or removing clothing and dousing the patient with cold water to maximize the water-vapor skin interface. ${ }^{94}$ Convection is then facilitated with air movement by fanning. Cooling by evaporation plus convection has been studied predominantly in patients with non-EHS, ${ }^{95}$ with mean cooling times of 40 to 68 min. ${ }^{91,96}$ Limited studies on traditional evaporative cooling have been done with EHS or heat exhaustion, with reported cooling rates half as fast as immersion cooling. ${ }^{97}$

Recommendation. Evaporative or convective cooling can be considered as adjunct cooling methods if cold water immersion is unavailable (1C).

\section{CHEMICAL COLD PACKS/ICE PACKS}

There is a traditional advocacy for the use of ice packs or chemical cold packs strategically applied to the skin covering the neck, axillae, and groin to cool blood flow passing in the major vessels as an adjunctive cooling measure. ${ }^{98}$
Limited studies show no benefit in heat reduction with ice packs or chemical cold packs applied to these areas. ${ }^{99,100}$ Ice packs have been found to have greater cooling capacity than chemical cold packs, ${ }^{101}$ and if used, are most efficacious when wet and covering the entire body (to optimize conductive cooling). ${ }^{99}$ A small translational study applied chemical cold packs to the glabrous skin of the palms, soles, and cheeks and found twice the cooling rate over traditional major vascular locations, ${ }^{102}$ using the high-capacity blood flow of the subcutaneous arteriovenous anastomoses.

Recommendations. Ice packs should be applied to cover the entire body (1C). If chemical cold packs are used, they should be applied to the cheeks, palms, and soles rather than the skin covering the major vessels (1C).

\section{ANTIPYRETICS}

As clinicians, we generally treat elevated temperatures with antipyretics. This class of medications, such as ibuprofen and aspirin, works by inhibiting prostaglandin formation, and acetaminophen lowers the thermoregulatory setpoint. ${ }^{103}$ Although this may be elevated in infectious causes of hyperthermia, this is not the case in exerciseinduced hyperthermia. Antipyretic drugs are ineffectual and should be avoided. ${ }^{104,105}$

Recommendation. Antipyretics should be avoided in heat illness (2B).

\section{Hospital treatment}

Generally, patients with heat stroke should be transported to a medical facility capable of critical care management of patients with multiple organ failure. Exceptions to this guideline have included soldiers or athletes treated in the field with ice-water immersion immediately at the onset of EHS with complete resolution of symptoms and subsequent observation in a medical station or infirmary. ${ }^{106,107}$ In a hospital setting, the primary goals of treatment for heat stroke are rapidly lowering core body temperature and supporting organ system function ${ }^{22}$ because patients may develop multiple organ failure with shock, acute respiratory failure, acute kidney injury, disseminated intravascular coagulopathy, and intestinal ischemia. Depending on the patient's clinical status, supportive treatment may include administering supplemental oxygen, performing intubation and mechanical ventilation, establishing adequate intravascular access, restoring intravascular volume with intravenous isotonic crystalloid solution, placing a bladder catheter to monitor urine output, and initiating vasopressors to support blood pressure (after adequate volume resuscitation). 
The evidence on different cooling methods has involved a heterogeneous range of subjects experiencing EHS or classic heat stroke. Of the studies comparing different cooling methods, those involving randomized trials generally have been performed on healthy volunteers with exerciseinduced hyperthermia and have enrolled relatively few subjects. The remaining studies on treating heat stroke patients have for the most part been case series reports or nonrandomized comparisons of treatment methods, with considerable variations in the baseline characteristics of subjects from one study to the next. Such heterogeneity and variation have reduced the comparative conclusions that can be drawn. Despite this limitation, the historical record has promoted 2 methods of cooling in a hospital setting: 1) conductive cooling via cold water immersion of the patient; and 2) evaporative and convective cooling via the application of sprayed water and forced air currents over the body.

\section{CONDUCTIVE COOLING}

Cold water immersion is safe and effective for young, athletic patients with EHS. A cooling protocol used for over $15 \mathrm{y}$ involving an ice-water slurry has been applied effectively with no fatalities or adverse effects in hundreds of civilian and military individuals. ${ }^{18,106,108}$ Agitation, intolerance, or combativeness may occur in encephalopathic heat stroke patients, and benefits of immersive cooling should be balanced with the theoretical concerns of impaired access to an immersed patient who may require advanced cardiac monitoring or resuscitation, especially among older patients. ${ }^{90,94,109}$ Cold-water immersion may be considered in non-EHS, although this may not be practical for the typically older patients with multiple comorbidities in the critical care environment. ${ }^{90,110}$ In the absence of cold-water immersion, wetted ice packs covering the entire body can cool through conduction. ${ }^{99}$

Recommendations. Cold water immersion should be considered for EHS in the hospital setting (1A). Cold water immersion can be considered for treatment of classic heat stroke patients (1C).

\section{EVAPORATIVE AND CONVECTIVE COOLING}

Evaporative cooling in elderly patients may offer several theoretical advantages, such as greater patient comfort and less agitation as well as easier access to patients who may need advanced monitoring or resuscitative procedures. In general, studies on evaporative and convective cooling have involved classic heat stroke patients and experimental volunteers with exercise-induced hyperthermia but not patients with actual EHS. The larger studies using a specially constructed device, termed a body cooling unit, have produced cooling rates ranging from 0.04 to $0.1^{\circ} \mathrm{C} \cdot \mathrm{min}^{-1}$, with an average cooling of time of 68 to 78 min and $10 \%$ mortality. ${ }^{94,95}$ No direct comparisons between the body cooling unit with cold water immersion are available, but extrapolation of cooling rates suggests evaporative and convective cooling is an order of magnitude less efficacious. Because classic heat stroke patients are more likely to be older, obese, and with medical conditions such as diabetes, high blood pressure, and heart disease, the evidence suggests that the evaporative plus convective cooling technique by wetting and fanning the skin has a passable hospital-based role in the treatment of classic heat stroke but cools more slowly than conductive cooling and is not indicated in EHS.

Recommendation. Evaporative and convective cooling may be considered in classic heat stroke in the hospital setting, but cooling rates with this method are inferior to those with conductive cooling. Evaporative and convective cooling is not indicated in EHS, unless effective conductive cooling is not available (1C).

\section{TARGET COOLING TEMPERATURES}

The target cooling temperatures of EHS and exerciseinduced hyperthermia to less than $39^{\circ} \mathrm{C}$ by ice water immersion have been well tolerated, with no fatalities, adverse outcomes, or core temperature "afterdrop" resulting in hypothermia. ${ }^{18,106,108,111}$ Practitioners should also be cautious of falsely elevated rectal temperature measurements in the recovery phase resulting from the insulating effect of body mass. ${ }^{112}$

Recommendation. Heat stroke patients should be cooled to a target temperature of no less than $39^{\circ} \mathrm{C}(1 \mathrm{~B})$.

\section{ADJUNCTIVE COOLING TREATMENTS}

If intravenous fluids are available, it is beneficial to use cold fluids $\left(4^{\circ} \mathrm{C}\right)$ whenever possible. These can decrease core temperature at a twofold rate compared with room temperature fluids but provide insufficient cooling as a primary treatment for heat stroke. More invasive techniques of body cavity lavage with cold isotonic fluid have been reported but have not been adequately studied. ${ }^{113,114}$ Intravascular cooling catheters are suggested to decrease morbidity when added to evaporative and convective cooling. ${ }^{115}$

Recommendations. Cold intravenous fluids should be given for adjunctive cooling in heat stroke (1C). Intravascular cooling catheters or cold water lavage are not recommended primary treatments for heat stroke (2C). 


\section{PHARMACOLOGIC TREATMENT}

No pharmacologic agent has been shown to be helpful as a treatment for heat stroke. Dantrolene has been used for treatment of malignant hyperthermia. It acts by impairing calcium release from the sarcoplasmic reticulum, thereby reducing the muscular rigidity and hypertonicity typical of this condition. A well-designed randomized clinical trial of dantrolene vs placebo in classic heat stroke found no difference in cooling rates or outcome, concluding that this pharmacologic treatment should not be used in heat stroke patients. $^{116}$

Recommendation. Dantrolene should be avoided for treatment of heat stroke patients (2B).

\section{Conclusion}

This article provides evidence-based guidelines for the prevention, recognition, and treatment of heat illness. Most of the available data are based on case series or extrapolation of results stemming from exercise-associated hyperthermia, which is an accepted research model, because randomized controlled trials for treatments of EHS are ethically challenging to justify. These guidelines apply the strength of the evidence to 2 distinct populations of heat stroke patients, and although the patient with EHS is more likely to be found in the wilderness environment, the medical provider should be aware of all therapeutic modalities and their inherent risks and benefits. We recommend that patients with heat stroke be cooled by conductive means by whole-body ice water or cold-water immersion (the preferential method in EHS). Evaporative and convective cooling of classic heat stroke may be augmented with the addition of ice packs over the entire body to promote conductive cooling. Future areas of research should include direct comparisons of available cooling modalities in controlled models, as well as further evaluation of endovascular catheters and hospital-based systems for optimum cooling of critical patients.

Author Contributions: All authors contributed to manuscript conceptualization, data collection and review, and manuscript preparation. Financial/Material Support: None.

Disclosures: None.

\section{Supplementary materials}

Supplementary material associated with this article can be found in the online version at doi:10.1016/j.wem.2018.10. 004.

\section{References}

1. Robine JM, Cheung SL, Le Roy S, Van Oyen H, Griffiths C, Michel JP, et al. Death toll exceeded 70,000 in Europe during the summer of 2003. C R Biol. 2008;331(2):171-8.

2. Xu J. QuickStats: Number of heat-related deaths, by sexnational vital statistics system, United States, 1999-2010. MMWR Morb Mortal Wkly Rep. 2012;61(36):729.

3. Gilchrist J, Haileyesus T, Murphy M, Comstock RD, Collins C, Yard E. Heat illness among high school athletes-United States, 2005-2009. MMWR Morb Mortal Wkly Rep. 2010;59(32):1009-13.

4. Centers of Disease Control and Prevention. Heat-related illnesses and deaths-United States, 1994-1995. MMWR Morb Mortal Wkly Rep. 1995;44(25):465-8.

5. Austin MG, Berry JW. Observations on one hundred cases of heatstroke. J Am Med Assoc. 1956;161(16):1525-9.

6. Adolph EF. Tolerance to heat and dehydration in several species of mammals. Am J Physiol. 1947;151(2):564-75.

7. Overgaard J, Suit HD. Time-temperature relationship in hyperthermic treatment of malignant and normal tissue in vivo. Cancer Res. 1979;39(8):3248-53.

8. Vicario SJ, Okabajue R, Haltom T. Rapid cooling in classic heatstroke: effect on mortality rates. Am J Emerg Med. 1986;4(5):394-8.

9. Lipman GS, Eifling KP, Ellis MA, Gaudio FG, Otten EM, Grissom CK. Wilderness Medical Society practice guidelines for the prevention and treatment of heat-related illness. Wilderness Environ Med. 2013;24(4):351-61.

10. Lipman GS, Eifling KP, Ellis MA, Gaudio FG, Otten EM, Grissom CK. Wilderness Medical Society practice guidelines for the prevention and treatment of heat-related illness: 2014 update. Wilderness Environ Med. 2014;25(4 Suppl): S55-65.

11. Noakes TD, Myburgh KH, du Plessis J, Lang L, Lambert M, van der Riet C, et al. Metabolic rate, not percent dehydration, predicts rectal temperature in marathon runners. Med Sci Sports Exerc. 1991;23(4):443-9.

12. Byrne C, Lee JK, Chew SA, Lim CL, Tan EY. Continuous thermoregulatory responses to mass-participation distance running in heat. Med Sci Sports Exerc. 2006;38(5):803-10.

13. Veltmeijer MT, Eijsvogels TM, Thijssen DH, Hopman MT. Incidence and predictors of exertional hyperthermia after a $15-\mathrm{km}$ road race in cool environmental conditions. J Sci Med Sport. 2015;18(3):333-7.

14. Lipman GS, Eifling KP, Ellis MA, Gaudio FG, Otten EM, Grissom CK. Keeping a broad perspective: reply regarding the Wilderness Medical Society practice guidelines for the prevention and treatment of heat-related illness. Wilderness Environ Med. 2014;25(2):251-2.

15. Nelson DA, Deuster PA, O'Connor FG, Kurina LM. Timing and predictors of mild and severe heat illness among new military enlistees. Med Sci Sports Exerc. 2018;50(8):1603-12.

16. Talbott JH, Michelsen J. Heat cramps. A clinical and chemical study. J Clin Invest. 1933;12(3):533-49. 
17. Schwellnus MP. Cause of exercise associated muscle cramps (EAMC)-altered neuromuscular control, dehydration or electrolyte depletion? Br J Sports Med. 2009;43(6):401-8.

18. Costrini AM, Pitt HA, Gustafson AB, Uddin DE. Cardiovascular and metabolic manifestations of heat stroke and severe heat exhaustion. Am J Med. 1979;66(2):296-302.

19. Asplund CA, O’Connor FG, Noakes TD. Exercise-associated collapse: an evidence-based review and primer for clinicians. Br J Sports Med. 2011;45(14):1157-62.

20. Casa DJ, DeMartini JK, Bergeron MF, Csillan D, Eichner ER, Lopez RM, et al. National Athletic Trainers' Association Position Statement: exertional heat illnesses. J Athl Train. 2015;50(9):986-1000.

21. Backer HD, Shopes E, Collins SL, Barkan H. Exertional heat illness and hyponatremia in hikers. Am J Emerg Med. 1999;17(6):532-9.

22. Bouchama A, Knochel JP. Heat stroke. $N$ Engl J Med. 2002;346(25):1978-88.

23. Sawka MN, Wenger CB. Physiological Responses to Acute Exercise-Heat Stress. Indianapolis, IN: Benchmark Press; 1988.

24. Rowell LB. Cardiovascular aspects of human thermoregulation. Circ Res. 1983;52(4):367-79.

25. Heller HC, Grahn DA. Enhancing thermal exchange in humans and practical applications. Disrupt Sci Technol. 2012;1(1):11-9.

26. Armstrong LE, Casa DJ, Millard-Stafford M, Moran DS, Pyne SW, Roberts WO. American College of Sports Medicine position stand. Exertional heat illness during training and competition. Med Sci Sports Exerc. 2007;39(3):556-72.

27. Leon LR, Helwig BG. Heat stroke: role of the systemic inflammatory response. $J$ Appl Physiol (1985). 2010;109(6):1980-8.

28. Sakaguchi Y, Stephens LC, Makino M, Kaneko T, Strebel FR, Danhauser LL, et al. Apoptosis in tumors and normal tissues induced by whole body hyperthermia in rats. Cancer Res. 1995;55(22):5459-64.

29. Buckley IK. A light and electron microscopic study of thermally injured cultured cells. Lab Invest. 1972;26(2):201-9.

30. Eberman LE, Cleary MA. Development of a heat-illness screening instrument using the Delphi panel technique. J Athl Train. 2011;46(2):176-84.

31. Toloo GS, Fitzgerald G, Aitken P, Verrall K, Tong S. Are heat warning systems effective? Environ Health. 2013;12:27.

32. Pryor RR, Bennett BL, O'Connor FG, Young JM, Asplund CA. Medical evaluation for exposure extremes: heat. Wilderness Environ Med. 2015;26(4 suppl):S69-75.

33. Pandolf KB, Gange RW, Latzka WA, Blank IH, Kraning II KK, Gonzalez RR. Human thermoregulatory responses during heat exposure after artificially induced sunburn. Am J Physiol. 1992;262(4 Pt 2):R610-6.

34. Pandolf KB, Gange RW, Latzka WA, Blank IH, Young AJ, Sawka MN. Human thermoregulatory responses during cold water immersion after artificially induced sunburn. Am J Physiol. 1992;262(4 Pt 2):R617-23.
35. Glazer JL. Management of heatstroke and heat exhaustion. Am Fam Physician. 2005;71(11):2133-40.

36. Bruning RS, Dahmus JD, Kenney WL, Alexander LM. Aspirin and clopidogrel alter core temperature and skin blood flow during heat stress. Med Sci Sports Exerc. 2013;45(4):674-82.

37. Bedno SA, Li Y, Han W, Cowan DN, Scott CT, Cavicchia MA, et al. Exertional heat illness among overweight US army recruits in basic training. Aviat Space Environ Med. 2010;81(2):107-11.

38. Brazaitis M, Skurvydas A. Heat acclimation does not reduce the impact of hyperthermia on central fatigue. Eur J Appl Physiol. 2010;109(4):771-8.

39. Cheung SS, McLellan TM. Heat acclimation, aerobic fitness, and hydration effects on tolerance during uncompensable heat stress. J Appl Physiol (1985). 1998;84(5):1731-9.

40. Garrett AT, Goosens NG, Rehrer NJ, Patterson MJ, Cotter JD. Induction and decay of short-term heat acclimation. Eur J Appl Physiol. 2009;107(6):659-70.

41. Weller AS, Linnane DM, Jonkman AG, Daanen HA. Quantification of the decay and re-induction of heat acclimation in dry-heat following 12 and 26 days without exposure to heat stress. Eur J Appl Physiol. 2007;102(1):57-66.

42. Daanen HA, Jonkman AG, Layden JD, Linnane DM, Weller AS. Optimising the acquisition and retention of heat acclimation. Intl J Sports Med. 2011;32(11):822-8.

43. Armstrong LE, De Luca JP, Hubbard RW. Time course of recovery and heat acclimation ability of prior exertional heatstroke patients. Med Sci Sports Exerc. 1990;22(1):36-48.

44. Kazman JB, Heled Y, Lisman PJ, Druyan A, Deuster PA, O'Connor FG. Exertional heat illness: the role of heat tolerance testing. Curr Sports Med Rep. 2013;12(2):101-5.

45. Johnson EC, Kolkhorst FW, Richburg A, Schmitz A, Martinez J, Armstrong LE. Specific exercise heat stress protocol for a triathlete's return from exertional heat stroke. Curr Sports Med Rep. 2013;12(2):106-9.

46. Sharwood KA, Collins M, Goedecke JH, Wilson G, Noakes TD. Weight changes, medical complications, and performance during an Ironman triathlon. Br J Sports Med. 2004;38(6):718-24.

47. Wharam PC, Speedy DB, Noakes TD, Thompson JM, Reid SA, Holtzhausen LM. NSAID use increases the risk of developing hyponatremia during an Ironman triathlon. Med Sci Sports Exerc. 2006;38(4):618-22.

48. Maughan RJ, Watson P, Shirreffs SM. Heat and cold: what does the environment do to the marathon runner? Sports Med. 2007;37(4-5):396-9.

49. Wall BA, Watson G, Peiffer JJ, Abbiss CR, Siegel R, Laursen PB. Current hydration guidelines are erroneous: dehydration does not impair exercise performance in the heat. Br J Sports Med. 2015;49(16):1077-83.

50. Sawka MN, Latzka WA, Matott RP, Montain SJ. Hydration effects on temperature regulation. Int J Sports Med. 1998;19(Suppl 2):S108-10. 
51. Sawka MN, Young AJ, Latzka WA, Neufer PD, Quigley MD, Pandolf KB. Human tolerance to heat strain during exercise: influence of hydration. J Appl Physiol (1985). 1992;73(1):368-75.

52. Duffield R, Steinbacher G, Fairchild TJ. The use of mixedmethod, part-body pre-cooling procedures for team-sport athletes training in the heat. J Strength Cond Res. 2009;23(9):2524-32.

53. Lemire B, Gagnon D, Jay O, Dorman L, DuCharme MB, Kenny GP. Influence of adiposity on cooling efficiency in hyperthermic individuals. Eur J Appl Physiol. 2008;104(1): 67-74.

54. Tenaglia SA, McLellan TM, Klentrou PP. Influence of menstrual cycle and oral contraceptives on tolerance to uncompensable heat stress. Eur J Appl Physiol Occup Physiol. 1999;80(2):76-83.

55. Bergeron MF, Devore C, Rice SG. Policy statement-Climatic heat stress and exercising children and adolescents. Pediatrics. 2011;128(3):e741-e7.

56. Basu R, Samet JM. Relation between elevated ambient temperature and mortality: a review of the epidemiologic evidence. Epidemiol Rev. 2002;24(2):190-202.

57. Bouchama A, Dehbi M, Mohamed G, Matthies F, Shoukri M, Menne B. Prognostic factors in heat wave related deaths: a meta-analysis. Arch Intern Med. 2007; 167(20):2170-6.

58. Nelson N, Eichna LW, Horvath SM, Shelley WB, Hatch TF. Thermal exchanges of man at high temperatures. Am J Physiol. 1947;151(2):626-52.

59. United States Department of the Navy, Bureau of Medicine and Surgery. Manual of Naval Preventive Medicine (NAVMED P-5010-3). Washington, DC: Department of the Navy, US Department of Defense; 2009.

60. Occupational Health and Safety Administration. OSHA Technical Manual (TED1-00-015). Washington, DC: Occupational Health and Safety Administration, US Department of Labor; 1999.

61. National Climactic Data Center. Heat Index Charts. Asheville, NC: National Oceanic and Atmospheric Administration, National Climactic Data Center; 2000.

62. Jackson LL, Rosenberg HR. Preventing heat-related illness among agricultural workers. J Agromedicine. 2010;15(3): $200-15$.

63. Armstrong LE, Johnson EC, Casa DJ, Ganio MS, McDermott BP, Yamamoto LM, et al. The American football uniform: uncompensable heat stress and hyperthermic exhaustion. J Athl Train. 2010;45(2):117-27.

64. Porter AM. Heat illness and soldiers. Mil Med. 1993;158(9): 606-9.

65. Biery Jr JC, Blivin SJ, Pyne SW. Training in ACSM black flag heat stress conditions: how US marines do it. Curr Sports Med Rep. 2010;9(3):148-54.

66. Armstrong LE, Crago AE, Adams R, Roberts WO, Maresh CM. Whole-body cooling of hyperthermic runners: comparison of two field therapies. Am J Emerg Med. 1996; 14(4):355-8.

67. Hadad E, Moran DS, Epstein Y. Cooling heat stroke patients by available field measures. Intensive Care Med. 2004;30(2): 338.

68. Hadad E, Rav-Acha M, Heled Y, Epstein Y, Moran DS. Heat stroke: a review of cooling methods. Sports Med. 2004;34(8):501-11.

69. Shapiro Y, Seidman DS. Field and clinical observations of exertional heat stroke patients. Med Sci Sports Exerc. 1990;22(1):6-14.

70. Schwellnus MP, Derman EW, Noakes TD. Aetiology of skeletal muscle 'cramps' during exercise: a novel hypothesis. J Sports Sci. 1997;15(3):277-85.

71. Lugo-Amador NM, Rothenhaus T, Moyer P. Heat-related illness. Emerg Med Clin North Am. 2004;22(2):315-27. viii.

72. Canpolat U, Bayazit Y, Aytemir K. Brugada syndrome unmasked by heat exhaustion. Ann Noninvasive Electrocardiol. 2017;22(1).

73. Molina Borao I, Calvo Galiano N, Urmeneta Ulloa J, Rivero Fernandez E, Oloriz Sanjuan T, Asso Abadia A. Heat wave: a trigger of electrical storm in a patient with Brugada syndrome. Rev Esp Cardiol (Engl Ed.). 2016;69(12):1228-30.

74. Binkley HM, Beckett J, Casa DJ, Kleiner DM, Plummer PE. National Athletic Trainers' Association position statement: exertional heat illnesses. J Athl Train. 2002;37(3):329-43.

75. Casa DJ, Becker SM, Ganio MS, Brown CM, Yeargin SW, Roti MW, et al. Validity of devices that assess body temperature during outdoor exercise in the heat. J Athl Train. 2007;42(3):333-42.

76. Gonzalez-Alonso J, Calbet JA, Nielsen B. Metabolic and thermodynamic responses to dehydration-induced reductions in muscle blood flow in exercising humans. J Physiol. 1999;520(Pt 2):577-89.

77. Casa DJ, Armstrong LE, Hillman SK, Montain SJ, Reiff RV, Rich BS, et al. National Athletic Trainers' Association position statement: fluid replacement for athletes. J Athl Train. 2000;35(2):212-24.

78. Lopez RM, Casa DJ, Jensen KA, DeMartini JK, Pagnotta KD, Ruiz RC, et al. Examining the influence of hydration status on physiological responses and running speed during trail running in the heat with controlled exercise intensity. J Strength Cond Res. 2011;25(11):2944-54.

79. Sawka MN. Physiological consequences of hypohydration: exercise performance and thermoregulation. Med Sci Sports Exerc. 1992;24(6):657-70.

80. Castellani JW, Maresh CM, Armstrong LE, Kenefick RW, Riebe D, Echegaray M, et al. Intravenous vs oral rehydration: effects on subsequent exercise-heat stress. J Appl Physiol (1985). 1997;82(3):799-806.

81. Epstein Y, Shani Y, Moran DS, Shapiro Y. Exertional heat stroke-the prevention of a medical emergency. J Basic Clin Physiol Pharmacol. 2000;11(4):395-401. 
82. Hostler D, Reis SE, Bednez JC, Kerin S, Suyama J. Comparison of active cooling devices with passive cooling for rehabilitation of firefighters performing exercise in thermal protective clothing: a report from the Fireground Rehab Evaluation (FIRE) trial. Prehosp Emerg Care. 2010;14(3): 300-9.

83. Hew-Butler T, Rosner MH, Fowkes-Godek S, Dugas JP, Hoffman MD, Lewis DP, et al. Statement of the Third International Exercise-Associated Hyponatremia Consensus Development Conference, Carlsbad, California, 2015. Clin J Sport Med. 2015;25(4):303-20.

84. McArdle WD, Magel JR, Lesmes GR, Pechar GS. Metabolic and cardiovascular adjustment to work in air and water at 18, 25, and $33^{\circ}$ C. J Appl Physiol. 1976;40(1):85-90.

85. Noakes TD. Body cooling as a method for reducing hyperthermia. S Afr Med J. 1986;70(6):373-4.

86. Proulx CI, Ducharme MB, Kenny GP. Effect of water temperature on cooling efficiency during hyperthermia in humans. J Appl Physiol (1985). 2003;94(4):1317-23.

87. Cooper KE. Physiology of hypothermia. Br J Anaesth. 1959;31(3):96-105.

88. Proulx CI, Ducharme MB, Kenny GP. Safe cooling limits from exercise-induced hyperthermia. Eur J Appl Physiol. 2006;96(4):434-45.

89. Wyndham CH, Strydom NB, Cooke HM, Maritz JS, Morrison JF, Fleming PW, et al. Methods of cooling subjects with hyperpyrexia. J Appl Physiol. 1959;14:771-6.

90. Ferris EB, Blankenhorn MA, Robinson HW, Cullen GE. Heat stroke: clinical and chemical observations on 44 cases. J Clin Invest. 1938;17(3):249-62.

91. Casa DJ, McDermott BP, Lee EC, Yeargin SW, Armstrong LE, Maresh CM. Cold water immersion: the gold standard for exertional heatstroke treatment. Exerc Sport Sci Rev. 2007;35(3):141-9.

92. O'Connor JP. Simple and effective method to lower body core temperatures of hyperthermic patients. Am J Emerg Med. 2017;35(6):881-4.

93. Costrini A. Emergency treatment of exertional heatstroke and comparison of whole body cooling techniques. Med Sci Sports Exerc. 1990;22(1):15-8.

94. Khogali M, Weiner JS. Heat stroke: report on 18 cases. Lancet. 1980;2(8189):276-8.

95. Khogali M, al Khawashi M. Heat stroke during the Makkah pilgrimage. Saudi Med J. 1981;2:85-93.

96. Al-Aska AK, Abu-Aisha H, Yaqub B, Al-Harthi SS, Sallam A. Simplified cooling bed for heatstroke. Lancet. 1987;1(8529):381.

97. Hee-Nee P, Rupeng M, Lee VJ, Chua WC, Seet B. Treatment of exertional heat injuries with portable body cooling unit in a mass endurance event. Am $J$ Emerg Med. 2010;28(2):246-8.

98. Platt M, Vicario S. Rosen's Emergency Medicine. 7th ed. Philadelphia, PA: Mosby; 2009.
99. Kielblock AJ, Van Rensburg JP, Franz RM. Body cooling as a method for reducing hyperthermia. An evaluation of techniques. S Afr Med J. 1986;69(6):378-80.

100. Richards D, Richards R, Schofield PJ, Ross V, Sutton JR. Management of heat exhaustion in Sydney's the Sun Cityto-Surf run runners. Med J Aust. 1979;2(9):457-61.

101. Phan S, Lissoway J, Lipman GS. Chemical cold packs may provide insufficient enthalpy change for treatment of hyperthermia. Wilderness Environ Med. 2013;24(1):37-41.

102. Lissoway JB, Lipman GS, Grahn DA, Cao VH, Shaheen M, Phan S, et al. Novel application of chemical cold packs for treatment of exercise-induced hyperthermia: a randomized controlled trial. Wilderness Environ Med. 2015;26(2): 173-9.

103. Saper CB, Breder CD. Endogenous pyrogens in the CNS: role in the febrile response. Prog Brain Res. 1992;93: 419-28. discussion 428-9.

104. Downey JA, Darling RC. Effect of salicylates on elevation of body temperature during exercise. J Appl Physiol. $1962 ; 17: 323-5$

105. Johnson SC, Ruhling RO. Aspirin in exercise-induced hyperthermia. Evidence for and against its role. Sports Med. 1985;2(1):1-7.

106. Beller GA, Boyd 3rd AE. Heat stroke: a report of 13 consecutive cases without mortality despite severe hyperpyrexia and neurologic dysfunction. Mil Med. 1975;140(7):464-7.

107. Demartini JK, Casa DJ, Stearns R, Belval L, Crago A, Davis R, et al. Effectiveness of cold water immersion in the treatment of exertional heat stroke at the Falmouth Road Race. Med Sci Sports Exerc. 2015;47(2):240-5.

108. O'Donnell Jr TF. Acute heat stroke. Epidemiologic, biochemical, renal, and coagulation studies. JAMA. 1975;234(8):824-8.

109. Bouchama A, Dehbi M, Chaves-Carballo E. Cooling and hemodynamic management in heatstroke: practical recommendations. Crit Care. 2007;11(3):R54.

110. Hart GR, Anderson RJ, Crumpler CP, Shulkin A, Reed G, Knochel JP. Epidemic classical heat stroke: clinical characteristics and course of 28 patients. Medicine (Baltimore). 1982;61(3):189-97.

111. Gagnon D, Lemire BB, Casa DJ, Kenny GP. Cold-water immersion and the treatment of hyperthermia: using $38.6^{\circ} \mathrm{C}$ as a safe rectal temperature cooling limit. J Athl Train. 2010;45(5):439-44.

112. Newsham KR, Saunders JE, Nordin ES. Comparison of rectal and tympanic thermometry during exercise. South Med J. 2002;95(8):804-10.

113. Smith JE. Cooling methods used in the treatment of exertional heat illness. Br J Sports Med. 2005;39(8):503-7. discussion 507.

114. Horowitz BZ. The golden hour in heat stroke: use of iced peritoneal lavage. Am J Emerg Med. 1989;7(6):616-9. 
115. Yokobori S, Koido Y, Shishido H, Hifumi T, Kawakita K, Okazaki T, et al. Feasibility and safety of intravascular temperature management for severe heatstroke: a prospective multicenter pilot study. Crit Care Med. 2018;46(7):e670-6.
116. Bouchama A, Cafege A, Devol EB, Labdi O, el-Assil K, Seraj M. Ineffectiveness of dantrolene sodium in the treatment of heatstroke. Crit Care Med. 1991;19(2): 176-80. 